\title{
Article \\ Effect of a Simvastatin-Impregnated Chitosan Scaffold on Cell Growth and Osteoblastic Differentiation
}

\author{
Ghaliah M. Alsawah *(D), Mohammad I. Al-Obaida and Ebtissam M. Al-Madi
}

check for

updates

Citation: Alsawah, G.M.; Al-Obaida, M.I.; Al-Madi, E.M. Effect of a Simvastatin-Impregnated Chitosan Scaffold on Cell Growth and Osteoblastic Differentiation. Appl. Sci. 2021, 11, 5346. https://doi.org/ 10.3390/app11125346

Academic Editors:

Gianrico Spagnuolo and

Marco Tatullo

Received: 23 May 2021

Accepted: 8 June 2021

Published: 9 June 2021

Publisher's Note: MDPI stays neutral with regard to jurisdictional claims in published maps and institutional affiliations.

Copyright: (c) 2021 by the authors. Licensee MDPI, Basel, Switzerland. This article is an open access article distributed under the terms and conditions of the Creative Commons Attribution (CC BY) license (https:// creativecommons.org/licenses/by/ $4.0 /)$.
Department of Restorative Dental Sciences, College of Dentistry, King Saud University, P.O. Box 68004, Riyadh 11527, Saudi Arabia; malobaida@ksu.edu.sa (M.I.A.-O.); ealmadi@ksu.edu.sa (E.M.A.-M.) * Correspondence: dr.galsawah@gmail.com

\begin{abstract}
This study aims to evaluate the effect of chitosan (CS) scaffold, alone, and the potential synergistic effect when impregnated with simvastatin (SIM), on immortalized human bone-marrow mesenchymal stem cells (hbMMSCs) compared to CollaCote (CL). CS scaffolds were fabricated and seeded with immortalized hBMMSCs. Samples were divided into control groups (negative with no added material and positive with CL added) and four experimental groups: CS alone, CS/SIM 0.01, 0.03 , and $0.05 \mathrm{mg}$, respectively. Cell viability, osteoblastic differentiation and calcium deposition were investigated via AlamarBlue, alkaline phosphate activity assays and alizarin red S staining at 1 and 14 days, respectively. At day one, no significant difference was noted between the groups regarding cell viability. However, all CS/SIM groups showed significant cutback at day 14 in cell proliferation compared to CS alone and CL groups $(p<0.001)$. All groups supported osteoblastic differentiation with no significant difference. Alkaline phosphate activity increased in both time periods in the CS/SIM $0.05 \mathrm{mg}$ group compared to the other SIM groups, with no significant difference among the experimental groups. Chitosan scaffold is a bioactive compatible material capable of regenerative potential of hBMMSCs and a promising material to be used for perforation repair.
\end{abstract}

Keywords: chitosan; differentiation; osteoblast; scaffold; simvastatin

\section{Introduction}

Tissue engineering (TE) is advancing fast in dentistry aiming to guide cell destiny into differentiating into osteo/odontoblastic cells. Successful tissue regeneration requires the presence of three main components: stem cells, growth factors, and a scaffold [1]. Preparing scaffolds seeded with different types of cells and growth factors is the most popular technique for TE [2]. Chitosan (CS) is a natural, nontoxic cationic biopolymer of glucosamine and $N$ acetylglucosamine obtained after partial alkaline deacetylation of chitin, the main component of crustacean exoskeletons [3]. Structurally, it is similar to glycosaminoglycans (GAGs), which are important structural elements of the extracellular matrix of many tissues [4]. Hence, it has generated great interest in multiple medical fields, particularly for TE and wound healing. CS is biocompatible and biodegradable into nontoxic components, and has hemostatic potential and anti-inflammatory and antimicrobial properties; it promotes cell adhesion, proliferation, and differentiation [3]. The adequate pore sizes of CS, and the ability to modify it and combine it with other polymers, have facilitated the development of a wide range of scaffolds for the regeneration of many tissues, including bone, neural and vascular tissues, cartilage, and skin [4]. Recently, a porous CS scaffold was produced and proven to be capable of increasing the regenerative potential of dental pulp cells and odontoblastic differentiation [5]. Furthermore, resolution of periapical lesions, increase in root thickness and length, and high vascularized connective tissues in the root canal space was shown histologically in regenerative endodontic procedures using chitosan scaffolds [6].

Simvastatin (SIM), a 3-hydroxy-3-methyl-glutaryl-coenzyme A reductase inhibitor, is a widely used statin and a well-established cholesterol-lowering drug [7]. Pioneering work demonstrated that statins, particularly SIM and lovastatin, increase the expression 
of bone morphogenic protein 2 (BMP-2) in osteoblasts and encourage bone formation [8]. Subsequent studies supported these findings, showing that statins continuously stimulate the expression of bone anabolic factors (e.g., vascular endothelial growth factor and BMP-2) and promote osteoblast differentiation and mineralization [8-10]. Additionally, statins suppress osteoclast differentiation which reflects positively on bone pathologies, such as osteoporotic fracture [11,12]. From an endodontic perspective, dental pulp stem cells treated with SIM showed increased odontogenic differentiation and accelerated formation of mineralized tissue, and are considered to be potential supplemental pulp-capping agents $[13,14]$. To our knowledge, no study has investigated the effect of CS scaffold, alone or with SIM impregnation, on human bone-marrow mesenchymal stem cells (hBMMSCs) and on osteoblastic differentiation specifically nor compared it to the most commonly used scaffold in endodontic wound healing, CollaCote (CL). In addition, no study has defined a known reliable SIM effective dose for cell proliferation and osteoblastic differentiation. Thus, the aim of this study was to develop CS scaffolds, with and without SIM, evaluate their effect and the potential synergistic outcome of the two materials on hBMMSCs and compare it to CollaCote. Two null hypotheses were tested:

1. There is no difference between the combined use of CS scaffold and SIM and their individual use in osteoblastic differentiation of hBMMSCs.

2. These scaffolds show no difference in osteoblastic differentiation when compared to CollaCote.

\section{Materials and Methods}

\subsection{Chitosan Scaffold Fabrication}

The study was approved by the ethics of committee and institutional review board of our corresponding institute (Project No. E-19-3930-May 2019). To prepare a polymeric solution, $1 \mathrm{~g}$ high-molecular-weight CS (Sigma-Aldrich, St. Louis, MO, USA) was dissolved in $20 \mathrm{~mL} \mathrm{5 \%}$ aqueous acetic acid (ReagentPlus ${ }^{\circledR}, \geq 99 \%$; Sigma-Aldrich, St. Louis, MO, USA) in a $100 \mathrm{~mL}$ flask at room temperature with continuous stirring. After complete dissolution, $1 \%$ SIM (Merck \& CO, Jersey, NJ, USA) was added with continuous stirring until the solution became very viscous. This solution was concentrated to $2 / 3$ by solvent evaporation then salt $(\mathrm{NaCl})$ microparticles sized between $80-120 \mu \mathrm{m}$ was used as porogen and immersed in the viscous solutions. The resulting suspensions were homogenized at room temperature by sonification for $20 \mathrm{~min}$ in an ultrasonic bath. The mixture was then cast on Teflon plates (Sirona, London, UK) and allowed to dry at $25^{\circ} \mathrm{C}$ for $24 \mathrm{~h}$, then under vacuum at $40^{\circ} \mathrm{C}$ for $48 \mathrm{~h}$. The porous scaffold was obtained by extraction of the porogen from the polymeric material, washing it five times in excess water to dissolve all of the $\mathrm{NaCl}$ porogens, followed by drying it again in a vacuum oven until constant mass achieved. The resulting scaffolds were $0.5 \mathrm{~mm}$-thick sheets of random dimensions, ready to be cut into the desired diameters $[5,15]$. The porous CS/SIM scaffold preparation steps are shown in Figure 1. 


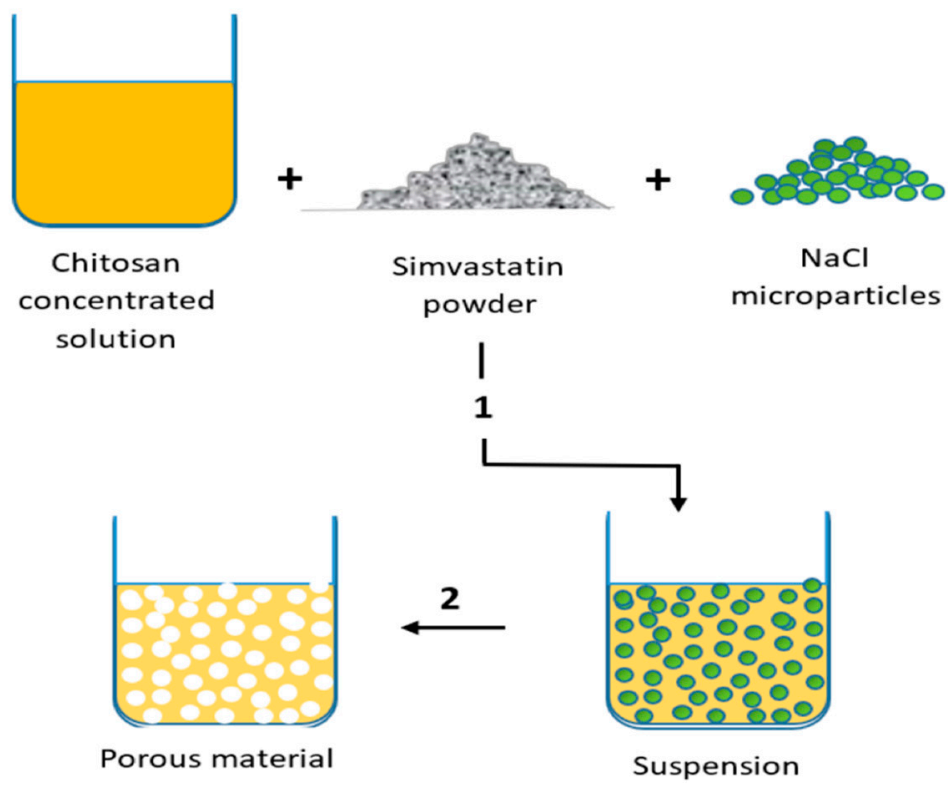

Figure 1. Preparation of porous chitosan/simvastatin scaffold. (1) Chitosan/simvastatin concentrated solution with NaCL microparticles used as porogens. (2) Porogen extraction to obtain porous scaffold.

\subsection{Scanning Electron Microscopy}

The overall surface and internal morphology of the scaffolds were examined by scanning electron microscopy (SEM) at $10 \mathrm{kv}$ (JSM-6360LV; JEOL Ltd., Tokyo, Japan). The specimens were mounted with double-sided adhesive on aluminum sample holders, and sputter coated with gold ( 20-30 nm thickness) to avoid charging during observation [5].

\subsection{Cell Culture}

Immortalized hBMMSCs (hTERTt-MSC-C1) were provided by the Stem Cell Laboratory, Medical College of King Saud University, King Khaled University Hospital, Riyadh, Saudi Arabia. The cells were cultured in Dulbecco's modified Eagle's medium (GlutaMAX ${ }^{\mathrm{TM}}$; Thermo Fisher, Los Angeles, CA, USA) supplemented with 10\% fatal bovine serum (Gibco, Carlsbad, Los Angeles, CA, USA), 100 $\times$ non-essential amino acid solution (UFC Biotech, Buffalo, NY, USA), and 100× penicillin-streptomycin (pen-strep) solution (UFC Biotech, Buffalo, NY, USA). The cultures were maintained at $37^{\circ} \mathrm{C}$ in a humidified atmosphere $(5 \%$ $\mathrm{CO}_{2}, 95 \%$ air) [16]. Cultures between the second and seventh passages were used.

\subsection{Scaffold Sterilization}

The scaffolds were cut into squares $(5 \times 5 \mathrm{~mm})$ and exposed to ultraviolet light for $30 \mathrm{~min}$. Then, $70 \%$ ethanol was applied, and the scaffolds were washed twice in phosphatebuffered saline (PBS) and left to dry for $10 \mathrm{~min}[5,16]$.

\subsection{Group Allocation}

The cells were divided into six groups: negative control, positive control with CollaCote (CUTANPLAST ${ }^{\circledR}$ DENTAL, Milan, Italy), CS alone, CS with $0.01 \mathrm{mg}$ SIM, CS with $0.03 \mathrm{mg}$ SIM, and CS with $0.05 \mathrm{mg}$ SIM.

\subsection{Examination of Osteogenic Differentiation}

The scaffolds were dispensed in 24-well and 94-well plates according to the group distribution and the cells were seeded at a density of 100,000/well after reaching $80 \%$ confluency. The cells were supplemented with $50 \mu \mathrm{g} / \mathrm{mL}$ L-ascorbic acid (Winlab Ltd., London, UK), 10 mM $\beta$-glycerophosphate (Sigma Aldrich, Munich, Germany), $100 \mathrm{nM}$ dexamethasone (Sigma Aldrich, Munich, Germany), $10 \mathrm{nM}$ cholecalciferol (Sigma Aldrich, Munich, Germany), and $100 \mathrm{U} / 10 \mu \mathrm{g}$ pen-strep solution (UFC Biotech, Buffalo, NY, USA). 
Cells in all groups were cultivated for 1 and 14 days in a humidified atmosphere, with changing of the media every 3 days, followed by continuous live cell observation under an Axiovert $40 \mathrm{C}$ light microscope (System Contraves \& Sec, Carl Zeiss, Thornwood, NY, USA).

Cell viability was tested using the alamarBlue $(\mathrm{AB})$ assay in the 94-well plate. $\mathrm{AB}$ dye (200 $\mu \mathrm{L}$; Thermo Fisher, LA, CA, USA) was added to each well, and the plate was covered with aluminum foil and incubated for $1 \mathrm{~h}$ at $37^{\circ} \mathrm{C}$ in a humidified atmosphere. Absorbance of the plate at $405 \mathrm{~nm}$ was then measured in a microplate reader (Synergy; BioTek Instruments, Winooski, VT, USA) $[5,16]$.

An alkaline phosphate (ALP) activity assay was used in the 24-well plate to examine osteoblastic differentiation. The wells were rinsed with $200 \mu \mathrm{L}$ PBS and fixed by the addition of $50 \mu \mathrm{L}$ fixative solution (3.7\% formaldehyde- $90 \%$ ethanol) (Sigma Aldrich, Munich, Germany), then incubated at room temperature for $30 \mathrm{~s}$. Next, $50 \mu \mathrm{L}$ p-nitrophenyl phosphate solution was added to each well to assay protein. The plate was covered with aluminum foil and incubated for $1 \mathrm{~h}$ at room temperature in the dark. The reaction was stopped by the addition of $20 \mu \mathrm{L}$ stop solution to each well. Absorbance of the plate at $405 \mathrm{~nm}$ was measured in a Synergy microplate reader (Synergy; BioTek Instruments, Winooski, VT, USA) [5,16].

To confirm calcium deposition, the specimens were set, in the same 24-well plate, with $4 \%$ paraformaldehyde in PBS solution for $15 \mathrm{~min}$ at room temperature. Next, each well was rinsed with $1 \mathrm{~mL}$ PBS, and $0.05 \mathrm{~mL}$ alizarin red $\mathrm{S}$ solution $\left(\mathrm{pH} 4.2\right.$; ScienCell ${ }^{\mathrm{TM}}$, Carlsbad, CA, USA) was added. The plate was covered with aluminum foil and incubated for $30 \mathrm{~min}$ at room temperature in the dark, with gentle rocking every $10 \mathrm{~min}$. The dye was removed, and the wells were washed seven times with distilled water. Followed by adding $1 \mathrm{~mL}$ of distilled water into each well to prevent the cells from drying out, and the samples were visualized and photographed (EOS 750D; Canon, Tokyo, Japan) under a light microscope (100 $\mu \mathrm{m}$, Axiovert 40C; System Contraves \& Sec, Carl Zeiss, Thornwood, NY, USA) [5,16]. All assays were performed in triplicate.

\subsection{Statistical Analysis}

Means and standard deviations were used to summarize the data, and one-way analysis of variance (ANOVA) and the Games-Howell post-hoc test were performed. Data from days 1 and 14 were compared using the paired-sample $t$-test. $p$ values $<0.05$ were considered to be significant. The SPSS software (ver.26.0 for Windows; IBM Corporation, Armonk, NY, USA) was used for data analysis.

\section{Results}

\subsection{Scaffold Morphology}

SEM revealed at the scaffold surface its homogenous architecture and confirmed the presence of SIM as particle aggregation in the SIM-impregnated CS scaffolds (Figure 2A-C).
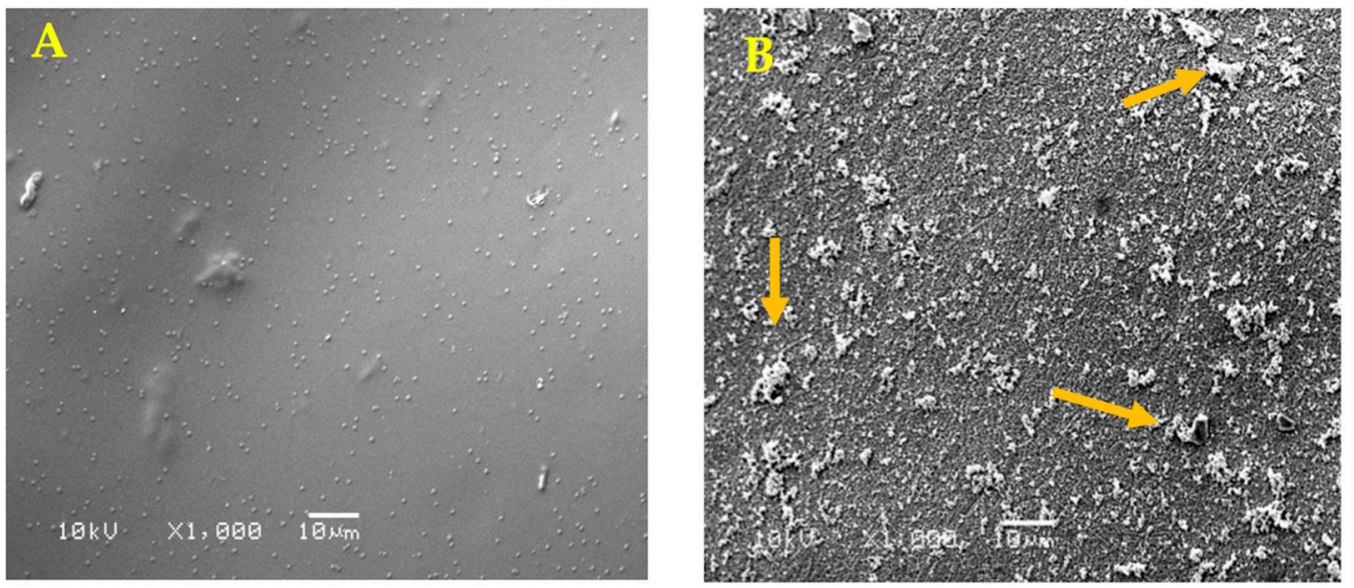

Figure 2. Conts. 


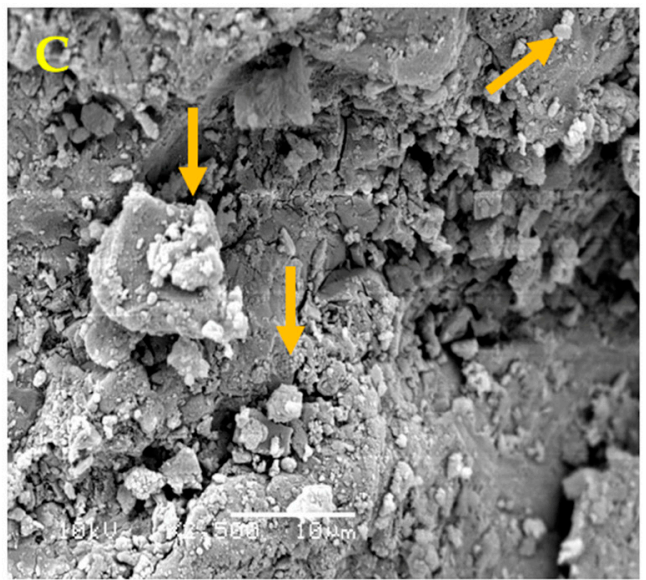

Figure 2. Scanning electron microscopic images of the (A) chitosan scaffold surface $(1000 \times)$, and (B) the chitosan scaffold surface with simvastatin $(1000 \times)$. (C) chitosan scaffold internal morphology $(2500 \times)$. Arrows indicate simvastatin presence.

\subsection{Osteogenic Differentiation}

All variable findings are summarized in Table 1.

Concerning cell viability, no significant difference was noted between the groups in Day $1(p=0.064)$. However, AB values were significantly lower at day 14 in all SIM groups when compared to CS alone and CollaCote groups, indicating a significant cutback in the cells proliferation when cultivated with SIM $(p<0.001)$ (Figure 3). No significant difference was noted between the groups regarding osteoblastic differentiation $(p>0.05)$. CS $/$ SIM $0.05 \mathrm{mg}$ increased ALP activity in both time periods compared with the other two SIM groups (Figure 4), however, these differences were not statistically significant between SIM groups nor between time periods $(p>0.05)$. Calcium deposition was presented by alizarin red $\mathrm{S}$ staining (Figure 5A,B).

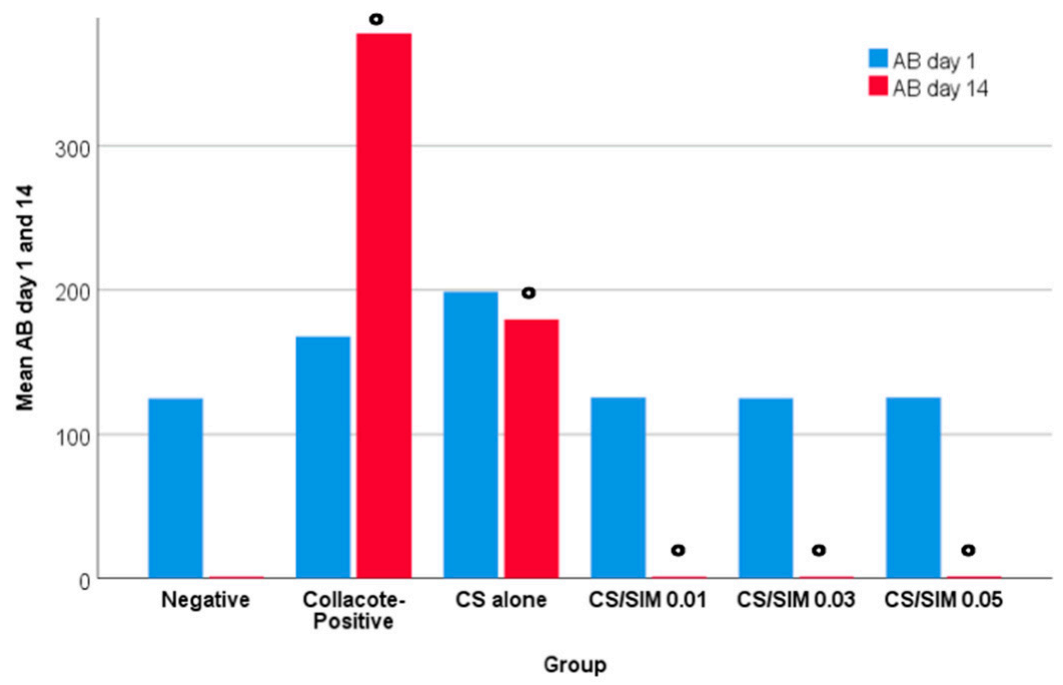

Figure 3. AlamarBlue values indicating cell viability on day 1 and $14 .^{\circ}$ a significant difference $(p<0.05)$. $\mathrm{AB}$, AlamarBlue; CS, chitosan; SIM, simvastatin. 


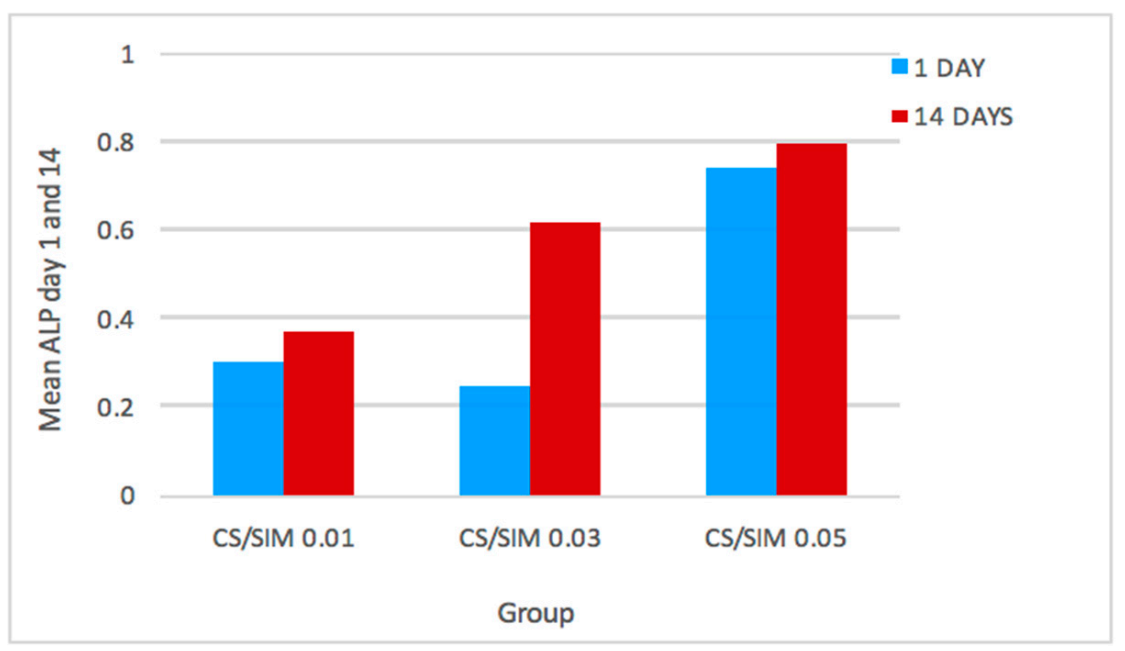

Figure 4. Alkaline phosphate activity for the SIM dose response on day 1 and 14. ALP, alkaline phosphate activity; CS, chitosan; SIM, simvastatin.

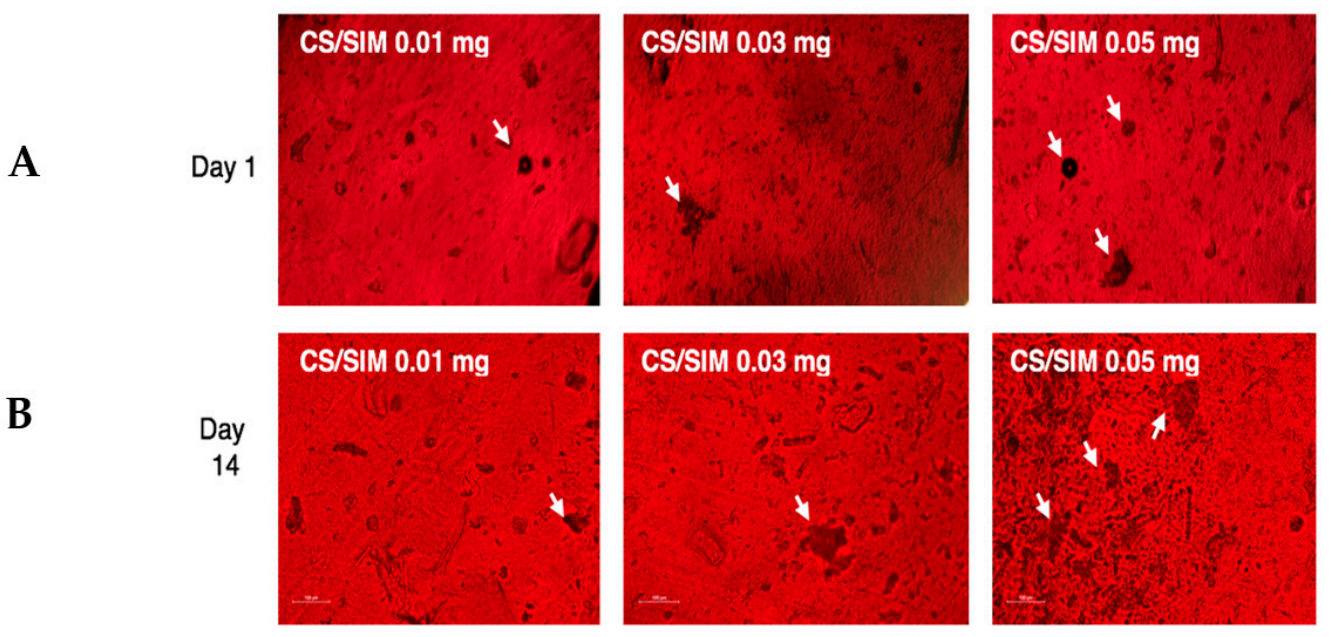

Figure 5. Alizarin red S staining images of the SIM dose response on (A) day 1 and (B) day 14. SIM, simvastatin. Arrows indicate mineralized matrix formation.

Table 1. AB and ALP data in days 1 and 14.

\begin{tabular}{ccccc}
\hline \multirow{2}{*}{ Group } & \multicolumn{2}{c}{ AB } & \multicolumn{2}{c}{ ALP } \\
\cline { 2 - 5 } & $\begin{array}{c}\text { Day 1 } \\
\text { Mean (SD) }\end{array}$ & $\begin{array}{c}\text { Day 14 } \\
\text { Mean (SD) }\end{array}$ & $\begin{array}{c}\text { Day 1 } \\
\text { Mean (SD) }\end{array}$ & $\begin{array}{c}\text { Day 14 } \\
\text { Mean (SD) }\end{array}$ \\
\hline Negative & $124.67(31.13)$ & $1.03(0.21)$ & $0.46(0.27)$ & $1.19(0.26)$ \\
Collacote-Positive & $167.83(29.63)$ & $378(132.55)$ & $0.64(0.19)$ & $1.05(0.36)$ \\
CS alone & $198.67(79.96)$ & $179.67(15.24)$ & $0.51(0.29)$ & $0.52(0.27)$ \\
CS/SIM 0.01 & $125.33(7.74)$ & $1.05(0.07)$ & $0.30(0.19)$ & $0.37(0.05)$ \\
CS/SIM 0.03 & $124.83(17.33)$ & $1.06(0.12)$ & $0.25(0.07)$ & $0.62(0.52)$ \\
CS/SIM 0.05 & $125.33(15.06)$ & $1.12(0.06)$ & $0.74(0.74)$ & $0.80(0.41)$ \\
\hline
\end{tabular}

AB: AlamarBlue, ALP: Alkaline Phosphatase, SD: Standard deviation, CS: Chitosan, SIM: Simvastatin.

\section{Discussion}

CS-based treatments have been proposed in dentistry to eliminate bacteria and promote dentin and bone remineralization [17]. Biological substances seeded in the scaffolds are released and implanted in the body, directly influencing the behavior of ingrowing cells and thereby increasing the amount and quality of tissue neogenesis [18]. Thus, we fabricated CS scaffolds, with and without SIM, and investigated their outcome when in 
contact to cells regarding their growth, osteoblast differentiation, and matrix mineralization. Previous studies have shown that both CS and SIM promote proliferation and osteoblastic/odontoblastic differentiation of mesenchymal stem cells, supported by ALP production, mineralization, and bone sialoprotein expression [5,16,19]. Furthermore, the incorporation of SIM into scaffolds including CS in previous in vitro studies showed no adverse effect on cell viability, enhanced cell proliferation, and mineralization [20,21]. Our results are in agreement with these studies in using CS alone, where the cells were able to proliferate and present differentiation patterns on the scaffold structure while SIM did not promote cell proliferation within all groups and only supported cell differentiation. The range of SIM doses is broad in the literature and varied values have been reported as optimum concentrations; 0.01-1 $\mu \mathrm{mol} / \mathrm{L}$ SIM was shown to have a stimulatory effect on osteoblastic/odontoblastic differentiation of mesenchymal stem cells (MSC) [14], $0.2 \mu \mathrm{M}$ SIM was found to be the ideal concentration for mouse bone marrow MSC proliferation [22], $10^{-8} \mathrm{M}$ was reported to be the optimum dose for periodontal ligament cell osteoblastic differentiation [23] and recently $0.1 \mu \mathrm{mol} / \mathrm{L}$ SIM was selected as the bioactive dose for dental pulp cell migration and odontoblastic differentiation [5]. Doses above $0.1 \mu \mathrm{M}$ were reported cytotoxic [24] and in other studies, $1 \mu \mathrm{M}$ and $5 \mu \mathrm{M}$ were reported as the cytotoxic doses that significantly inhibited MSC proliferation [24,25]. Furthermore, SIM concentrations higher than $0.5 \mathrm{mM}$ showed a reduction in cell proliferation [22]. These different findings can be explained in that statins induce their beneficial effect on cell proliferation only at specific concentrations and can be highly cytotoxic if above the optimum concentration level. In addition to concentration, statins' hydrophilicity or hydrophobicity can regulate their cellular toxicity $[26,27]$. SIM molecule hydrophobicity enables passive penetration into cell membranes causing its cytotoxicity thus inhibiting cell proliferation [26]. While we chose to evaluate lower doses, based on the nearest aims of these studies to our research purpose [5], we can still assume that they had some cytotoxic effects. Overall, statins enhance the expression of proteins associated with osteogenic differentiation, increasing the activity of ALP which is fundamental for extracellular matrix (ECM) formation and osteogenic differentiation indicating osteoblast maturation [27]. The regenerative potential of SIM-supplemented CS scaffolds was reported to be dose-dependent $[14,22,23]$. However, our results showed no significant differences between the groups. Few studies declared different time point outcome, yet mineralization with SIM was found to be time dependent [9], which was in agreement with our ALP activity values and mineralization results but not with the AB values. The encountered differences between our present investigation and previously achieved results are probably due to the wide variety of SIM concentrations used in the literature, and our focus on the hBMMSCs osteoblastic differentiation rather than the different types of MSCs and odontoblastic differentiation investigated in the previous studies. Chitosan scaffolds contribute a promising role in osteoblastic differentiation and mineralization. This scaffold similarity to GAGs increased its desirable characteristics and advantageous outcome. Furthermore, the positively charged amine group $\left(\mathrm{NH}_{3}{ }^{+}\right)$plays an important role in establishing an electrostatic bonding with GAGs from host tissue hence allowing CS to interact with the surrounding extracellular matrix with no foreign body reaction. In addition, the $\mathrm{NH}^{3+} \mathrm{NH}_{3}{ }^{+}$establishes $\mathrm{CS}$ ability of cross-linking which indicates the possibility of the drug release, polymer degradation rate, and mechanical properties to be modulated [4]. Additionally, new tissue deposition can benefit from the CS porous architecture growing inside its structure, especially when loaded with drug generating a faster and more direct impact on the behavior of ingrowing cells. Hence, CS-SIM scaffolds are convenient for TE due to their ability to provide a biocompatible and bioactive scaffold capable of stimulating the osteogenic potential of host cells. Therefore, these scaffolds can be considered an interesting potential material for osteogenic differentiation and perforation repair clinically. Nevertheless, bearing in mind the limitations encountered in this in vitro study, further research should be conducted to determine the ideal SIM concentration for scaffold loading for bone regeneration, to examine the timing of its release and activity, and to expand the research of in vivo models. 


\title{
5. Conclusions
}

$\mathrm{CL}$ and CS have shown cell growth and regenerative potential which is essential in bone tissue healing and perforation repair clinically. However, SIM showed controversial results, hence, adding it to a scaffold might not be clinically significant.

\begin{abstract}
Author Contributions: Conceptualization, G.M.A. and M.I.A.-O.; methodology, G.M.A. and M.I.A.O.; validation, M.I.A.-O.; formal analysis, G.M.A. and M.I.A.-O.; investigation, G.M.A. and M.I.A.-O.; writing-original draft preparation, G.M.A., M.I.A.-O., and E.M.A.-M.; writing-review and editing, M.I.A.-O. and E.M.A.-M.; visualization, M.I.A.-O.; supervision, M.I.A.-O.; project administration, M.I.A.-O. All authors have read and agreed to the published version of the manuscript.
\end{abstract}

Funding: This research received no external funding.

Institutional Review Board Statement: Not applicable.

Informed Consent Statement: Not applicable.

Data Availability Statement: Details are presented within the article in the form of tables, figures, and images in results. Additional data will be made available upon request from the corresponding author.

Acknowledgments: The authors acknowledge Taieb Aouak and Waseem Saeed from the Chemistry Department of The College of Science, King Saud University (KSU), for their technical support in chitosan membrane fabrication. We also appreciate the contributions of the staff of the College of Dentistry Research Centre and Molecular Cell Biology Laboratory of KSU, and the College of Dentistry in collaboration with Naif bin AbdulAziz Health Research Centre.

Conflicts of Interest: The authors declare no conflict of interest.

\section{References}

1. Murray, P.E.; Garcia-Godoy, F.; Hargreaves, K.M. Regenerative Endodontics: A Review of Current Status and a Call for Action. J. Endod. 2007, 33, 377-390. [CrossRef]

2. Baldino, L.; Cardea, S.; Maffulli, N.; Reverchon, E. Regeneration techniques for bone-to-tendon and muscle-to-tendon interfaces reconstruction. Br. Med. Bull. 2016, 117, 25-37. [CrossRef] [PubMed]

3. Li, Q.; Dunn, E.; Grandmaison, E.; Goosen, M. Applications and Properties of Chitosan. J. Bioact. Compat. Polym. 1992, 7, 370-397. [CrossRef]

4. Kim, I.-Y.; Seo, S.-J.; Moon, H.-S.; Yoo, M.-K.; Park, I.-Y.; Kim, B.-C.; Cho, C.-S. Chitosan and its derivatives for tissue engineering applications. Biotechnol. Adv. 2008, 26, 1-21. [CrossRef]

5. Soares, D.; Anovazzi, G.; Bordini, E.A.F.; Zuta, U.O.; Leite, M.L.A.S.; Basso, F.G.; Hebling, J.; Costa, C.A.D.S. Biological Analysis of Simvastatin-releasing Chitosan Scaffold as a Cell-free System for Pulp-dentin Regeneration. J. Endod. 2018, 44, 971-976.e1. [CrossRef] [PubMed]

6. Palma, P.J.; Ramos, J.C.; Martins, J.B.; Diogenes, A.; Figueiredo, M.H.; Ferreira, P.; Viegas, C.; Santos, J.M. Histologic Evalu-ation of Regenerative Endodontic Procedures with the Use of Chitosan Scaffolds in Immature Dog Teeth with Apical Peri-odontitis. J. Endod. 2017, 43, 1279-1287. [CrossRef] [PubMed]

7. Schachter, M. Chemical, pharmacokinetic and pharmacodynamic properties of statins: An update. Fundam. Clin. Pharmacol. 2004, 19, 117-125. [CrossRef]

8. Mundy, G.; Garrett, R.; Harris, S.; Chan, J.; Chen, D.; Rossini, G.; Boyce, B.; Zhao, M.; Gutierrez, G. Stimulation of Bone Formation in Vitro and in Rodents by Statins. Science 1999, 286, 1946-1949. [CrossRef]

9. Maeda, T.; Kawane, T.; Horiuchi, N. Statins Augment Vascular Endothelial Growth Factor Expression in Osteoblastic Cells via Inhibition of Protein Prenylation. Endocrinology 2003, 144, 681-692. [CrossRef]

10. Maeda, T.; Matsunuma, A.; Kurahashi, I.; Yanagawa, T.; Yoshida, H.; Horiuchi, N. Induction of osteoblast differentiation indices by statins in MC3T3-E1 cells. J. Cell. Biochem. 2004, 92, 458-471. [CrossRef] [PubMed]

11. Ayukawa, Y.; Yasukawa, E.; Moriyama, Y.; Ogino, Y.; Wada, H.; Atsuta, I.; Koyano, K. Local application of statin promotes bone repair through the suppression of osteoclasts and the enhancement of osteoblasts at bone-healing sites in rats. Oral Surg. Oral Med. Oral Pathol. Oral Radiol. Endodontol. 2009, 107, 336-342. [CrossRef] [PubMed]

12. Pacheco-Pantoja, E.L.; Alvarez-Nemegyei, J. Statins and osteoporosis: A latent promise. Reumatol. Clín. 2014, 10, 201-203. [CrossRef] [PubMed]

13. Miyazawa, A.; Matsuno, T.; Asano, K.; Tabata, Y.; Satoh, T. Controlled release of simvastatin from biodegradable hydrogels promotes odontoblastic differentiation. Dent. Mater. J. 2015, 34, 466-474. [CrossRef]

14. Jia, W.; Zhao, Y.; Yang, J.; Wang, W.; Wang, X.; Ling, L.; Ge, L. Simvastatin Promotes Dental Pulp Stem Cell-induced Coronal Pulp Regeneration in Pulpotomized Teeth. J. Endod. 2016, 42, 1049-1054. [CrossRef] 
15. Al Rez, M.F.; Elnakady, Y.A.; Fouad, H.; Khalil, K.A.; Albarrag, A.M.; Elsarnagawy, T.; Mahmood, A.; Ansari, S.G. Fabrication and Characterization of Polycaprolactone Micro and Nanofibers for Vascular Tissue Replacement. Sci. Adv. Mater. 2015, 7, $599-605$. [CrossRef]

16. Abuelreich, S.; Manikandan, M.; Aldahmash, A.; Alfayez, M.; Al Rez, M.F.; Fouad, H.; Hashem, M.; Ansari, S.G.; Al-Jassir, F.F.; Mahmood, A. Human Bone Marrow MSCs form Cartilage and Mineralized Tissue on Chitosan/Polycaprolactone (CS/PCL) Combined Nanofibrous Scaffolds. J. Nanosci. Nanotechnol. 2017, 17, 1771-1778. [CrossRef]

17. Shrestha, A.; Hamblin, M.R.; Kishen, A. Characterization of a Conjugate between Rose Bengal and Chitosan for Targeted Antibiofilm and Tissue Stabilization Effects as a Potential Treatment of Infected Dentin. Antimicrob. Agents Chemother. 2012, 56, 4876-4884. [CrossRef] [PubMed]

18. Shrestha, S.; Kishen, A. Bioactive Molecule Delivery Systems for Dentin-pulp Tissue Engineering. J. Endod. 2017, 43, 733-744. [CrossRef]

19. Baek, K.H.; Lee, W.Y.; Oh, K.W.; Tae, H.J.; Lee, J.M.; Lee, E.J.; Han, J.H.; Kang, M.I.; Cha, B.Y.; Lee, K.W.; et al. The Effect of Simvastatin on the Proliferation and Differentiation of Human Bone Marrow Stromal Cells. J. Korean Med. Sci. 2005, 20, 438-444. [CrossRef]

20. Gentile, P.; Nandagiri, V.K.; Daly, J.; Chiono, V.; Mattu, C.; Tonda-Turo, C.; Ciardelli, G.; Ramtoola, Z. Localised controlled release of simvastatin from porous chitosan-gelatin scaffolds engrafted with simvastatin loaded PLGA-microparticles for bone tissue engineering application. Mater. Sci. Eng. C Mater. Biol. Appl. 2016, 59, 249-257. [CrossRef]

21. Nath, S.D.; Linh, N.T.; Sadiasa, A.; Lee, B.T. Encapsulation of simvastatin in PLGA microspheres loaded into hydrogel loaded BCP porous spongy scaffold as a controlled drug delivery system for bone tissue regeneration. J. Biomater. Appl. 2014, 28, 1151-1163. [CrossRef]

22. Liu, Y.-S.; Ou, M.-E.; Liu, H.; Gu, M.; Lv, L.-W.; Fan, C.; Chen, T.; Zhao, X.-H.; Jin, C.-Y.; Zhang, X.; et al. The effect of simvastatin on chemotactic capability of SDF-1 $\alpha$ and the promotion of bone regeneration. Biomaterials 2014, 35, 4489-4498. [CrossRef] [PubMed]

23. Yazawa, H.; Zimmermann, B.; Asami, Y.; Bernimoulin, J.-P. Simvastatin Promotes Cell Metabolism, Proliferation, and Osteoblastic Differentiation in Human Periodontal Ligament Cells. J. Periodontol. 2005, 76, 295-302. [CrossRef]

24. Pullisaar, H.; Reseland, J.E.; Haugen, H.J.; Brinchmann, J.E.; Østrup, E. Simvastatin coating of TiO2 scaffold induces osteogenic differentiation of human adipose tissue-derived mesenchymal stem cells. Biochem. Biophys. Res. Commun. 2014, 447, 139-144. [CrossRef]

25. Huang, X.; Huang, Z.; Li, W. Highly efficient release of simvastatin from simvastatin-loaded calcium sulphate scaffolds enhances segmental bone regeneration in rabbits. Mol. Med. Rep. 2014, 9, 2152-2158. [CrossRef] [PubMed]

26. Kupcsik, L.; Meurya, T.; Flury, M.; Stoddart, M.; Alini, M. Statin-induced calcification in human mesenchymal stem cells is cell death related. J. Cell. Mol. Med. 2009, 13, 4465-4473. [CrossRef]

27. Gorabi, A.M.; Kiaie, N.; Pirro, M.; Bianconi, V.; Jamialahmadi, T.; Sahebkar, A. Effects of statins on the biological features of mesenchymal stem cells and therapeutic implications. Heart Fail. Rev. 2020, 1-14. [CrossRef] [PubMed] 